\title{
Pediatric SARS-CoV-2 Infection in India: Expert Opinion without Evidence Leading to Public Health Policy
} Paralysis

\author{
Varnit Shanker $^{1,2 *}$ and Pooja Shanker ${ }^{1,3}$ \\ ${ }^{1}$ Department of Pediatrics and Neonatology, DACH, India \\ ${ }^{2}$ ALM Candidate, HES, Harvard University, USA \\ ${ }^{3}$ Center for Active Research Diagnostics and Infection Surveillance, Jaipur, India
}

\section{Letter}

By January 2021, sections of scientific community started to believe that India had overcome the pandemic and acquired herd immunity [1]. In March, 2021 the Indian government cited results from serological surveys and India's main computer model predicting disease spread in the "endgame" of the pandemic [2]. It was followed by national negligence of social-distancing norms, non-compliance of personal protective measures, mass political and social congregations. Double mutant SARS-CoV-2 virus variant and systemic shortfalls in immunization program emerged as unfortunate and man-made crises respectively. As a result, by August, 2021 India is expected to witness 1 million deaths from CoVID-19 [3].

Probably an intelligence of hindsight has potentiated many commentators to exert that current state of Indian pandemic scenario was well predicted. However, literature and references are lacking in support of concrete-confident scientific advice prior to onset of tragedy. Scientists in turn, legitimately so, have pointed towards gross underreporting of CoVID-19 statistics, political influence, ancient cultural mindset (such as, flowing river Ganga will cleanse the corona virus), over a dozen asynchronous CoVID-19 committees with no accountability, lack of cross specialty approach (virology, epidemiology, medicine, immunology etc) and delayed travel restrictions without stringent quarantine protocols [4-6]. This insight into the Indian healthcare system is critical to prevent repetition of such restricted scientific temperament.

In May, 2021, virologists and CoVID technical advisory committee, warned that children will be widely affected in the third wave of pandemic. It was added that the centre and state governments should make urgent arrangements to handle flurry of paediatric cases between the month of October and December 2021. Lack of CoVID immunization in this age group was the basis of this hypothesis [7]. Experts coming out in support of this argument added that the first wave affected elderly predominantly and the second wave is affecting young adults, hence by stretching the trends, next wave should affect even younger population that is children. The strength of scientific argument is questionable here, however, it went largely unchallenged in the clinical and academic circuits.

Children were not immunized even in the first and second wave, but still they have been clinically spared until now (Table 1) [11]. CoVID-19 affected paediatric population has been predominantly asymptomatic [8]. Another key opinion national leader added that the virus needs a host to survive and therefore will mutate itself to affect children. An acceptable argument from an evolutionary biology point of view, but it still doesn't explain why children, as new hosts, have been relatively spared until now [9]. The SARS-CoV-2 virus severely affecting adults below 50 years of age does not necessarily translate into a negative impact on children in the third wave. It is a speculation without foundation of basic sciences. However, academicians and clinicians have fiercely advocated this idea with an exponential propagation that hospitals need to be ready for a children-loving version of CoVID [10]. These expert opinions resulted in a series of potentially unnecessary decisions by the Indian institutions who felt compelled to react to this speculation wave.

Following these expert comments, May 5, 2021 onwards the Supreme Court of India, central and state governments proceeded to focus on capacity building of paediatric ICUs, immunization strategy for under 18 and ensure resource

*Corresponding author: Varnit Shanker, Department of Pediatrics and Neonatology, DACH, India; ALM Candidate, HES, Harvard University, USA

Accepted: June 22, 2021

Published online: June 24, 2021

Citation: Shanker V, Shanker P (2021) Pediatric SARS-CoV-2 Infection in India: Expert Opinion without Evidence Leading to Public Health Policy Paralysis . Arch Fam Med Gen Pract 6(1):174-175 
Citation: Shanker V, Shanker P (2021) Pediatric SARS-CoV-2 Infection in India: Expert Opinion without Evidence Leading to Public Health Policy Paralysis . Arch Fam Med Gen Pract 6(1):174-175

Table 1: Confirmed and Suspected cases of COVIS-19 in South East Asia Region (SEAR). Proportion of stratified paediatric population has remained constant temporally [11].

\begin{tabular}{|c|c|c|c|c|c|c|c|c|}
\hline Age group & Und & ars & & & 10 & & Over & ears \\
\hline Suspected / Confirmed $\rightarrow$ & Cases & $\%$ & Cases & $\%$ & Cases & $\%$ & Cases & $\%$ \\
\hline 30 Dec 19 - 30 Jun 20 & 5 & 0.9 & 6 & 1.1 & 6 & 1.1 & 505 & 96.7 \\
\hline 1 Jul 20 - 30 Dec 20 & 9043 & 2.4 & 8389 & 2.2 & 12544 & 3.3 & 342442 & 91.9 \\
\hline 1 Jan 21 - 19 Apr 21 & 21166 & 2.5 & 21870 & 2.5 & 31473 & 3.7 & 766817 & 91.1 \\
\hline Overall & 30214 & 2.4 & 30265 & 2.5 & 44023 & 3.6 & 1109764 & 91.4 \\
\hline
\end{tabular}

availability in paediatric units [12,13]. Far sightedness in public health is critical, but triage of priorities should take precedence. All these developments were taking place when India needed to focus on the current ongoing crisis including severe shortage of hospital beds, absence of oxygen availability, overburdened and exhausted healthcare officials. In a resource starved setting, the public health machinery appeared to digress from handling the current situation and create hysteria for parents. Policy makers and healthcare workers got invested in preparation of hypothetical scenario. Further, instead of utilizing readily available resources of paediatric critical care setups, they were reserved for possible future use. It is almost equivocally accepted that various CoVID response committee's efforts would have been better utilized in the management of ongoing crisis.

\section{References}

1. Bhuyan A (2021) Experts criticise India's complacency over COVID-19. Lancet 397: 1611-612.

2. Padma TV (2021) Indian government should heed its scientists on COVID. Nature 593: 9.

3. (2021) India's COVID-19 emergency. The Lancet 397: 1683.
4. (2021) 'Maa Ganga's blessings in flow, there should be no corona': U'khand CM on Kumbh. The Wire.

5. Koushika SP (2020) Misinformation and myths go viral. Nature India COVID-19 Special 32-33.

6. Ghosh A (2021) Too many cooks? 15 committees, dozens of experts behind India's fumbling Covid response. The Print.

7. Akshatha M (2021) Third wave of Covid-19 will hit children in a big way: Virologist Dr V Ravi. The Economic Times.

8. Balasubramanian S, Rao NM, Goenka A, et al. (20200 Coronavirus disease 2019 (COVID-19) in children-what we know so far and what we do not. Indian Pediatr 57: 435-442.

9. Pandey K (2021) 3rd wave to attack kids under 12; vaccinate the parents, quickly: Dr Devi Shetty. Times Now News.

10. (2021) Children more likely to get caught in COVID waves: Expert. The Indian Express.

11. COVID-19 cases and deaths with age and sex reported. (2021) WHO COVID dashboard: World Health Organization.

12. Supreme Court asks Centre to prepare for third wave of COVID-19. (2021) Business Today.

13. Nair G (2021) Start preparing to shield children in third Covid-19 wave, Pune Platform tells hospitals. Financial Express.

DOI: $10.36959 / 577 / 501$

Copyright: (C) 2021 Shanker V, et al. This is an open-access article distributed under the terms of the Creative Commons Attribution License, which permits unrestricted use, distribution, and reproduction in any medium, provided the original author and source are credited. 